\title{
The global environmental problem of the XXI century, new realities
}

\author{
Natalya Frolova* \\ Khabarovsk State University of Economics and Law, Tikhookeanskaya street, 134, 680042 \\ Khabarovsk, Russia
}

\begin{abstract}
The article analyzes the global environmental problem in its traditional aspects, such as a decrease in forest area, degradation of land resources, air pollution, as well as in its new features - a global pandemic. The article initially presents the concept of a global environmental problem from the perspective of foreign and domestic scientists, as well as international organizations. Further, the analysis of the manifestation of the global environmental problem is carried out in terms of quantitative indicators: reduction of forest area, land degradation, air pollution. The author outlines such an aspect of a global environmental problem as zoonotic infections, that is, the transfer of viruses from animals to humans. Under new conditions, the spread of viruses is accelerating, they easily overcome the species barrier, cause infection of the human body. The transmission of viruses on a global scale is becoming a new reality. At the same time, there are also "side" manifestations of the virus associated with its impact on the socio-economic development of individual countries, the impact on the policy of world economic relations. In conclusion, the author describes specific ways of solving the global environmental problem, both for individual countries and the world in general.
\end{abstract}

\section{Introduction}

Globalization implies the expansion, deepening, and intensification of interconnections on a planetary scale between all aspects of society. "The world is turning into a single social space, formed under the influence of a sophisticated interweaving of economic and technogenic factors" [8].

The consequence of the globalization of global systems is the emergence of a single cultural, informational, legal, and economic space at the international level. The phenomenon of world globalization is not reduced to the economic sphere but affects all key spheres of society - ideology, culture, and politics. At the same time, the active life of a person significantly affects the ecological system of the earth; it gradually loses its ability to self-regulation and reproduction: non-renewable natural resources are exhausted; renewable natural resources have no time to recover. Potential climate change under the influence of the "greenhouse effect", namely an increase in the concentration in the atmosphere of fuel combustion emissions from industrial enterprises and large cities as

${ }^{*}$ Corresponding author: frolova.nc@rambler.ru 
energy consumers is turning into an obvious threat. All of the above phenomena intensify and exacerbate the manifestation of the global environmental problem.

\section{Methods and types of the Earth's remote sensing}

The concept of "global environmental problem" is considered by both domestic and foreign scientists; the study of its aspects by international organizations is no less important.

The academic dictionary by Kotlyakov and Komarova defines an environmental problem as a tense state of the relationship between nature and society when the development of human society does not correspond to the ecological capabilities of the biosphere.

Reims N.F. presents an environmental problem as a phenomenon associated with human impacts on nature and the reverse effects of nature on a person and his economy, manifested in the intensification of natural disasters, climate change, etc.

According to the definition by Kuznetsova L.M., Nikolaev A.S., a global environmental problem is a gradual accumulation of negative changes in the biosphere, which led to a onetime catastrophic change in environmental parameters.

According to Shadzhe A.E., Sirotyuk E.A., an environmental pr oblem lies in the contradiction arising in the relationship between man and nature and associated with an unreasonable approach to the use of natural resources, pollution of habitats, etc.

Burko R. A. in his work "Environmental problems of modern society and ways to solve them" gives the following definition of an environmental problem - a change in the natural environment, as a result of anthropogenic influences or natural disasters, leading to a violation of the structure and functioning of nature.

The Charter of the United Nations (UN) does not specifically mention the environment, based on resolution 2398 (XXIII) of December 3, 1968, however, from the UN point of view, the development of a global environmental problem is associated with profound environmental changes in the context of development modern science and technology. It should be understood to mean the problems associated with the ongoing and ever-rapid deterioration of the quality of the human environment, affecting the living conditions of a person, his physical, mental, and social well-being, his dignity, and his enjoyment of basic human rights in both developing and developed countries.

According to Greenpeace, the international environmental organization, the global environmental problem is those associated with catastrophic environmental pollution, requiring the unification and joint participation of all countries in their solution.

Based on the conclusions of the 72nd session of the World Health Assembly on April 18, 2019, the global environmental problem, according to the World Health Organization, implies the presence of environmental risks to health, which are defined as any environmental physical, chemical, biological factors and factors associated with work activities that are external to the person, as well as all related forms of behavior.

Multiple analytical reports of the UN on environmental problems contain a comprehensive analysis of individual aspects of the environmental problem, as well as ways to solve it .

The theoretical aspects of the impact of pandemics on socio-economic development are described in the works by world organizations such as the World Bank, the World Health Organization, and many others. The scientific works by foreign authors deal with school closings and restrictions on social interactions and the impact of these processes on economic development in a pandemic (Borse et al., 2011). The impact of the pandemic on the workforce is being explored (Orsi. \& Santos, 2010). 


\section{Analysis of the main ERS data sources for the DEM development}

At the present stage of the world economy, the environmental problem is significantly aggravated. This is due to the difficult ecological situation in the forest, land, and water resources of the planet; problems are associated with the disappearance of various species of flora and fauna.

For many decades, forest areas have been steadily declining. Forests are cleared and replaced by arable, meadow, or grazing land. The struggle to expand the area of agricultural land is due to population growth and an increase in food needs. Thus, according to the Food and Agriculture Organization (FAO), the highest annual net forest loss in 2010-2020 was in Africa - 3.9 million hectares. Annual net forest loss in South America 2010-2020 amounted to 2.6 million hectares. The rate of net forest loss in South America has declined significantly, to about half the rate in 2010-2020. While, compared to 2000-2010, Asia had the highest net forest area growth in 2010-2020.

Over the 30 years from 1990 to 2020, the world's forest area has decreased by about 178 million hectares. At the same time, the rate of net forest loss during this period decreased significantly due to the decrease in deforestation in some countries, as well as the increase in a forest area in others due to afforestation and natural expansion of forests.

A positive trend is that net forest loss has decreased from 7.8 million ha per year in 1990-2000 up to 5.2 million hectares in 2000-2010, and 4.7 million hectares per year in 2010-2020. The decline in the rate of net forest loss has slowed down as a result of the decline in the rate of forest expansion.

A forest-related issue is a deforestation, which FAO defines as the conversion of forest to other land uses (regardless of whether it is caused by human activities). An estimated 420 million hectares of forest have been lost worldwide as a result of deforestation since 1990, while the rate of deforestation has slowed significantly. In the last five-year period (2015-2020), annual deforestation was estimated at 10 million hectares, up from 12 million hectares in 2010-2015. The world's forest resources continue to decline, mainly due to anthropogenic pressures arising from the need to meet the industrial and social demand for economic growth (Enaruvbe \& Atafo, 2016).

Fires intensify the environmental problem of forest resources. In 2015, about 98 million hectares of forest were affected by fire, mainly in the tropical zone.

Over the past 30 years, the area of natural forests has significantly decreased and, despite replanting, continues to decline. It should be noted, however, that there are still at least 1.11 billion hectares of primary forests in the world. Together, the three countries Brazil, Canada, and the Russian Federation - contain more than half (61 percent) of the world's primary forest. However, the primary forest area has declined by 81 million hectares since 1990, with the rate of loss more than doubling in 2010-2020 compared to the previous decade.

The environmental problem associated with the use of land resources is manifested in their degradation, which affects one-fifth of the entire earth's land (more than 2 billion hectares). Land degradation undermines the livelihoods of an estimated 3.2 billion people, leading to the extinction of species and exacerbating climate change. In 2000-2015, global land cover trends have resulted in a net reduction in uncultivated and semi-developed land. This decline was due to both direct and indirect factors such as deforestation, depleted farming practices, urbanization, land tenure rights, and poverty. Land-use change is not only one of the main causes of land degradation, but also one of the main routes for the spread of new infectious diseases.

The area of cultivated agricultural land (arable land, orchards, plantations) is 1507 million hectares or $11.2 \%$ of the total land fund of the planet. The most plowed part of the 
world is Europe (32\% is arable land). Among the largest countries in the world are India $(54 \%)$ and Argentina (40\%), with a particularly high degree of plowed land. At the same time, areas under urban development, roads, mining and water management facilities, and other infrastructure are growing.

The next factor of the global environmental problem today is air pollution. Air pollution is a serious threat to health and the climate, starting from smog hanging over cities to smoke inside the house. According to the World Health Organization, the cumulative exposure to polluted air in the environment and in everyday life causes about 7 million premature deaths every year.

The main air pollutants are carbon, nitrogen, sulfur, ozone, and particulate matter. They are all greenhouse gases. However, the largest percentage of greenhouse gases is hydrocarbons.

Most often, the source of hydrocarbon (CO2) pollution is the burning of fossil fuels such as coal, oil, and gas. Air emissions are then calculated following the UN Framework Convention on Climate Change methodology (in accordance with the 2006 Intergovernmental Panel on Climate Change Guidelines for National Greenhouse Gas Inventories). At the moment, statistics on emissions from fuel burning in the world are available for 1990-2019.

In 2019 , the combustion of coal, oil, and natural gas released $44 \%, 33 \%$, and $23 \%$ of all harmful substances into the atmosphere, respectively. This suggests that coal and oil are still the main sources of energy in the world, which in turn aggravates the state of the natural environment, increasing the degree of atmospheric pollution, despite a slight decrease in total emissions.

In 2019, CO2 emissions from fuel combustion decreased by $0.2 \%$ after two years of growth due to a significant increase in energy intensity, namely $2.1 \%$ in 2019 and a significant decrease in $\mathrm{CO} 2$ emissions per $\mathrm{kWh}$ produced $(-3.2 \%)$ mainly due to the switch from coal to gas and an increase in the share of renewable energy sources in the global energy balance.

The US (-2.4\%) and Europe (-3.9\%, with significant reductions in Germany, Poland, the United Kingdom, Spain, and Turkey) reached the greatest reduction in emissions as a result of lower energy demand (particularly in the energy sector), slower economic growth, moderate temperatures, and use of alternative fuel in the energy sector.

In Asia, CO2 emissions have risen, albeit at a slower pace than in recent years. In China, emissions rose for the third year in a row $(+2.8 \%)$, due to the tempered policy of switching from coal to gas. In contrast, in India, greenhouse gas emissions have declined (higher hydropower production has reduced coal consumption), as well as in South Korea (temporary shutdown of coal-fired power plants and a switch from coal to LNG) and Japan (lower electricity consumption and increased nuclear readiness reduced heat production).

In coal and hydrocarbon producing countries such as Russia, Australia, Iran, South Africa, or Algeria, CO2 emissions continue to grow.

The main and most serious changes in the composition of the atmosphere occur precisely as a result of the concentration of carbon dioxide in it, which in turn causes the "greenhouse effect". This effect leads to global warming, which, in turn, destabilizes dynamic processes in the atmosphere.

Thus, it can be concluded that since 1990 the emissions of pollutants, and greenhouse gases, into the atmosphere in the world are not unambiguous. In some years, their volume grew rapidly and slightly decreased. The largest share of pollutants enters the atmosphere as a result of coal combustion and production. This poses a danger both for the environment and for the world economy in general.

An acute effect of the environmental problem is the pollution of the water surface of the earth, as a consequence of human production activities. Some states discharge liquid and 
solid radioactive waste into the waters of the World Ocean. This waste is especially abundant in the northwestern part of the Atlantic Ocean. There are such discharges in the Pacific Ocean. Most of the radioactive waste buried in the ocean comes from the UK (76.5\%), Switzerland (9.6\%), and the United States (7.6\%).

The results of long-term observations showed that the quality of water in rivers and reservoirs tends to deteriorate - the number of sections increases annually, the level of water pollution in which is or exceeds 10 MPC. The most common substances polluting surface waters are petroleum products, phenols, easily oxidized organic substances, copper compounds, specific pollutants: aniline, lignin, lignosulfonates, methanol, etc.

For example, according to the UN, as a result of damage to the oil tanks of one of the tankers in July 2020, about 1.1 million barrels of oil spilled into the Red Sea, which in itself is an environmental disaster that threatens the life of coastal settlements, the state of the polluted water area in general, not to mention already about aquatic biological resources. Even the timely elimination of the consequences of an accidental oil and oil product spill does not cancel out the damage caused to the environment during the entire time of the response and the implementation of emergency rescue operations.

Thus, it is obvious that the man-made damage to the aquatic environment and the pollution of the oceans causes the depletion of its biological resources.

The ongoing ocean acidification threatens marine environments and ecosystem services. The ocean is the planet's largest carbon sink: it absorbs about $23 \% \mathrm{t}$ of the $\mathrm{CO} 2$ emissions from human activity annually and helps mitigate the effects of climate change. However, $\mathrm{CO} 2$ absorption leads to acidification of seawater, as evidenced by a $26 \%$ drop in $\mathrm{pH}$ compared to pre-industrial times. Ocean acidification threatens coral reefs and other critical species that are the backbone of the marine food chain and negatively impacts marine ecosystem services, including fisheries and aquaculture, coastal protection, transport links, and tourism. As ocean acidification increases, its ability to absorb $\mathrm{CO} 2$ from the atmosphere and to mitigate the effects of climate change decreases. Information from the new Ocean Acidification Data Portal indicates an increase in $\mathrm{pH}$ variance (up to $10-30 \%$ over the past five years) and an increase in ocean acidity. By the end of this century, a 100$150 \%$ increase in acidity is projected, affecting half of all marine organisms.

The share of fish stocks sufficient to support biological reproduction declined from $90.0 \%$ in 1974 to $66.7 \%$ in 2015 and $65.8 \%$ in 2017. Despite the continuing deterioration of the situation, its pace has slowed down in recent years. While this is encouraging, the progress achieved is not enough to prevent the depletion of some of the world's fish stocks in the medium term: larger measures are needed to restore stocks to a level that supports biological reproduction. In 2017, the Mediterranean and Black Seas retained the smallest proportion of stocks fished at a biological level (37.5\%), followed by the Southeast Pacific (45.5\%), and the Southwest Atlantic (46.7\%). On the contrary, the largest share (over 83\%) was recorded at the eastern end of the central, southwestern, and northeastern Pacific Ocean. While in the Southwest Pacific Ocean the share of such stocks increased by 10.5 percentage points compared to the 2015 level, in the Northwest Pacific and the Northwest Atlantic Ocean there was a significant decrease in this indicator: by 17.3 and 17.7 percentage points, respectively.

The manifestation or aggravation of a global environmental problem causes the spread of infectious diseases.

$75 \%$ of all the new infectious diseases, such as avian influenza and Ebola are zoonotic, namely transmitted from animals to humans. Transmission occurs as a result of human contact with contaminated wildlife and is usually associated with human intrusion into the natural habitat of animals and their activities, such as illegal trade in wildlife, disrupt ecosystems. 
According to scientists, the COVID-19 virus originated in the wild and passed the species barrier to humans. Currently, it is believed that the main source of the spread of the virus is horseshoe bats, which in turn transmitted the virus to an intermediate carrier. Human contact with intermediate carriers has facilitated the transmission of the pathogen, triggering a pandemic that, at the time of this writing, has spread to more than 140 countries, has infected more than 150,000 people, and incalculable damage [3].

According to another opinion, the situation is due to the illegal trafficking of African and Asian scaly anteaters. This particular mammal likely became an intermediary animal through which the coronavirus got from wild bats to people. Their meat is sold in "wild markets", where the coronavirus could enter the human body. Since 2014, the number of "whole pangolin equivalents" seized from smugglers worldwide has increased tenfold. Wildlife crimes, such as the illegal capture and trafficking of pangolins and other animals, do more than threaten ecosystem health and biodiversity. They have the potential to harm human health, economic development, and security around the world.

The SARS epidemic in 2003 was caused by the transmission of the virus from animals to humans, with the pathogen that caused the SARS epidemic in 2003, transmitted to humans from civets sold on the market as pets and delicacies.

In 2012, camels became the source of the zoonotic Middle East respiratory syndrome (MERS) virus. Avian influenza, Nipah virus, Ebola virus, and many other new infectious diseases have arisen in animals and have been transmitted to humans. This phenomenon is qualified as a zoonosis. It is estimated that over $60 \%$ of all noncommunicable diseases in the world are zoonotic infections, and the vast majority (over 70\%) of these zoonotic infections occur in the wild.

The coronavirus outbreak demonstrates that zoonotic infections originating in the wild pose a huge threat to public health, biosecurity, and even global security. At the same time, the factors of the rapid spread of the infection are its unknown nature, the lack of comprehensive treatment of the disease, and, accordingly, the unwillingness of people to resist the virus.

Another factor of the significant spread of coronavirus is globalization, which involves considering the world on a single planetary scale through the development of international air transportation, world cruise routes, and the development of global value chains for goods and services.

\section{Conclusions}

Modern conditions give rise to a natural question about reducing the aggravation of the global environmental problem in all its manifestations, especially in the new realities, when the entire planet is covered by its consequences.

On the one hand, the changes will affect the economic behavior of business entities. It will be necessary to develop mechanisms for "economic survival" in the new conditions, to modify the business architecture in the context of the global recession. Deglobalization processes are possible, a gradual departure from the use of global value chains, the inevitable increase in the influence of nationalism, manifested in placing their own national interests "above all else" [7].

On the other hand, behavioral changes, mainly to avoid coronavirus infection, have had a cascading indirect effect of the pathogen on the environment, reducing the concentration of some greenhouse gases in the atmosphere, altering air quality and pollution, and manmade noise (Lashley $\mathrm{M}$ et al., 2020). It is also required to maintain this state of equilibrium, to understand that mass consumption and global production "kill" our planet.

The traditional ways of solving the issue are the development of the concept of "sustainable development", which is understood as the ability of all human communities, 
including the most disadvantaged, to satisfy their basic needs - for housing, drinking water, food, a satisfactory level of health care and hygiene, participation in the adoption decisions, social cohesion, social fabric, cultural and spiritual expression, etc. This implies the adaptation of technologies and lifestyles to the socio-economic and environmental capabilities of each region, covering costs from internal sources, and creating biocompatible systems.

Thanks to this approach, the sustainable development of human civilization turns into a multifaceted process. It aims to strike a balance between the environmental, economic, and social spheres and to have regard to political (participation and democratization), ethical (responsibility, solidarity, social justice, and sufficiency), and cultural (local diversity and artistic creativity) considerations.

To address the climate problem and sustainable development, the world's largest banks in the UN community have presented the Principles for Responsible Finance since 2019. Within the framework of these principles, banks must build their business following the goals of the Paris Agreement on climate and sustainable development goals. These principles include alignment of the financial institution's business strategy with the sustainable development goals and the Paris Agreement; regulation of impact on the environment and society, as well as setting normative indicators for them; responsible work with clients and consumers, etc. (Savchenko and Zvorykina, 2020). The agreement is aimed at stimulating countries to change their economies towards low-carbohydrate production by phasing out traditional mining and processing technologies and replacing them with more environmentally friendly ones.

The International Monetary Fund proposes measures aimed at slowing the spread of coronavirus infection: increasing health care costs, informing the population about the severity of the crisis and the need to change personal behavior, international cooperation between countries in implementing measures to help vulnerable citizens. Certain areas relate to the activities of Central Banks, in particular, the provision of liquidity to maintain the functioning of the market and to reduce stress in key markets; easing monetary policy to maintain demand and confidence; implementation of temporary measures to assist the most affected sectors and many others [6].

Other measures include international cooperation to ensure an effective public health response based on a strong scientific consensus on the causes of disease and its mitigation; and the use of information technology to combat the pandemic, in terms of forecasting, modeling outbreaks, the development of remote technologies of Internet resources to ensure accessibility for people in developing countries.

Some countries are developing "green ecology" programs; in particular, in China, the concept of building an ecological civilization is proposed. It is based on Confucian ideology, which is grounded on the containment of consumption. In 2015, Xi Jipin proposed the concept of building a community with a common destiny for all mankind, "based on inclusive green development. Confucian attitudes towards consumption and harmony [11]. Within the framework of this direction, there was a proposal to create the One Belt One Road initiative, which involves the creation of global transport, industrial, technological, financial, and humanitarian infrastructure under the control of the PRC. This model implies the creation of conditions for the growth of incomes of the population, subsequently creating demand and markets, opportunities to buy more expensive "green" goods.

The Chinese experience shows the distribution of areas of responsibility between the market and the government for the development of a green economy. Chinese scientists have proposed a Triple P business model (People, Planet, Profitability), which combines the interests of society, nature, and private business. 
To summarize the above, we can say that the global pandemic reminds us of the relevance of maintaining a balance in nature and the need to ensure its sustainability. Measures to address the global environmental problem should be prioritized.

\section{References}

1. Resolution 1318 on globalization and sustainable development (2003), https://www.coe.int/

2. World globalization, http://www.iccwbo.ru/

3. Coronavirus and the pangolin effect: expanding interaction with wildlife leads to threats to health, biosecurity, and global security, https://blogs.worldbank.org/

4. R. Borse, C. Barton, T. Dumanovsky, J. Zucker, D. Swerdlow, P. Edelson, J. ChoeCastillo, M. Meltzer, Clinical Infectious Diseases, 52(1), 168 (2011)

5. M. Orsi, J. Santos, IEEE Transactions on Systems, Man, and Cybernetics, Part A: Systems and Humans, 40(2), 301 (2010)

6. Glory O. Enaruvbe, Ozien P. Atafo, Journal of Land Use Science, 11(1), 113(2016)

7. Marcus Lashley, Miguel Acevedo, Sehoya Cotner, How the ecology and evolution of the COVID-19 pandemic changed learning (2020)

8. Finance and Development, 57(2) (2020), https://www.imf.org/

9. V.S. Savchenko, Iu.V. Zvorykina, Russian Foreign Economic Bulletin, 5, 48 (2020)

10. The COVID-19 crisis bailout policy measures

11. A.N. Zakharov, D.B. Kalashnikov, Russian Foreign Economic Bulletin, 1, 41 (2020) 